DE DE GRUYTER

OPEN

Polish Cartographical Review

Vol. 47, 2015, no. 1, pp. 5-17

DOI: $10.1515 / p c r-2015-0001$

JOLANTA KORYCKA-SKORUPA

Departament of Geoinformatics, Cartography and Remote Sensing

Faculty of Geography and Regional Studies, University of Warsaw

j.skorupa@uw.edu.pl

\title{
Effectiveness of cartographic presentation methods applied within small-scale thematic maps in the press and on the Internet
}

\begin{abstract}
The author discuss effectiveness of cartographic presentations. The article includes opinions of cartographers regarding effectiveness, readability and efficiency of a map. It reminds the principles of map graphic design in order to verify them using examples of small-scale thematic maps.

The following questions have been asked: Is the map effective? Why is the map effective? How do cartographic presentation methods affect effectiveness of the cartographic message? What else can influence effectiveness of a map?

Each graphic presentation should be effective, as its purpose is to complete written word, draw the recipients' attention, make text more readable, expose the most important information. Such a significant role of graphics results in the fact that graphic presentations (maps, diagrams) require proper preparation.

Users need to have a chance to understand the graphics language in order to draw correct conclusions about the presented phenomenon. Graphics should demonstrate the most important elements, some tendencies, and directions of changes. It should generalize and present a given subject from a slightly different perspective.

There are numerous examples of well-edited and poorly edited small-scale thematic maps. They include maps, which are impossible to interpret correctly. They are burdened with methodological defects and they cannot fulfill their task.

Cartography practice indicates that the principles related to graphic design of cartographic presentation are frequently omitted during the process of developing small-scale thematic maps used - among others - in the press and on the Internet. The purpose of such presentations is to quickly interpret them. On such maps editors' problems with the selection of an appropriate symbol and graphic variable (fig. 1A, 9B) are visible. Sometimes they use symbols which are not sufficiently distinguishable nor demonstrative (fig. 11), it does not increase their readability. Sometime authors try too hard to reflect presented phenomenon and therefore the map becomes more difficult to interpret (fig. $4 A, B$ ). The lack of graphic sense resulting in the lack of graphic balance and aesthetics constitutes a weak point of numerous cartographic presentations (fig. 13).

Effectiveness of cartographic presentations consists of knowledge and skills of the map editor, as well as the recipients' perception capabilities and their readiness to read and interpret maps. The qualifications of the map editor should include methodological qualifications supported by the knowledge of the principles for cartographic symbol design, as well as relevant technical qualifications, which allow to properly use the tools to edit a map. Maps facilitate the understanding of texts they accompany and they present relationships between phenomenon better than texts, appealing to the senses.
\end{abstract}

Keywords: effectiveness of cartographic presentations, readability of maps, Internet maps, press maps, map graphic

\section{Introduction}

EFFECTIVENESS is a word which has a very broad meaning in Polish. On one hand EFFECTIVE means efficient, effectual and adequate, on the other hand it means significant and real (www.sjp.pl, www.wiktionary.org). Therefore we can talk about effective sales, effective management, effective learning, effective rehabilitation, effective communication.

It is worth taking a closer look at effectiveness in the context of cartographic presentation. Is the map effective? Why is the map effective? How do cartographic presentation 
methods affect effectiveness of cartographic information? What else can influence the effectiveness of a map?

Studies which aim at determining the effectiveness of maps have been conducted in cartography for a very long time. The trend in studies on the bordering between cartography and psychology cannot be defined differently. It occurred especially in Canada and the United States of America in the 60 s and 70 s of the 20th century. The manner of interpreting information presented on maps was studied and the perception of maps expressed through the correctness of diagram size estimation and value scale in a choropleth map was analyzed (K.-T. Chang 1976, H. Meihoefer 1969, J. Mościbroda 1992). Practically at the same time techniques associated with eye-tracking (T. Opach, 2011) were involved in the studies of maps. The first attempt to assess the correctness and readability of maps were initiated and they took place through the analysis of eye tracking, in other words through the recreation of the manner in which a user reads a map and to which elements of the map they pay special attention. Such studies have been popular up until now and they are used to - among others - assess the appearance and functionality of websites and Internet portals.

"Effective map design" was mentioned by A.H. Robinson (1960) more than fifty years ago. He highlighted that it is necessary to apply rules associated with readability of maps, visual balance, hierarchical organization and systematic analysis of the purpose, scale and nature of presented phenomenon, recipient's capabilities, etc. W. Ostrowski $(1974,1979)$ addressed this issues in a different way, writing about ,the efficiency of a map", in other words the development of a map in such a way, the consequence of which is its readability and correct interpretation.

K.A. Saliszczew (1998) conditioned "readability" of a map by the distinguishability of signs applied on the map, its illustration and the logic of their selection. These considerations led to the formulation of the principles of graphic map design (P. Kowalski, W. Ostrowski 2007):

- the principle of sufficient symbol visibility (visual variables identification),

- the principle of symbol distinguishability,

- the principle of simple symbol recognition (through symbol illustration and their com- pliance with the convention),

- the principle of logical connection between symbol form and map content (through hierarchical organization and graphic symbol grouping),

- the principle of symbol spatial operability (adjustment of symbol graphic form to the spatial nature of objects),

- the principle of graphic balance and aesthetics of a map.

Therefore an effective map is a map which respects the above mentioned principles. Each graphic presentations should be effective by definition, as its task is to complete written word, gain the recipients' attention, make text readable and highlight the most important information. The saying "an image speaks more than a thousand words" is very true. When text is completed by graphics we reach for it more willingly, we can notice what is important quicker and we show more interest in the subject. Such an important role of graphics results in the fact that graphic presentation (maps, diagrams) requires appropriate preparation. An editor-in-chief should have extensive professional and technical qualifications, and the selection of presentation methods cannot be coincidental.

The user needs to have a chance to "decode" the graphic's language in order to correctly interpret presented phenomenon. Only then graphics can do their job properly. It should not be used to present exactly what was described in the accompanying text. The purpose of graphics is to maintain some specific details of a given presentation. Graphics should present the most essential elements, tendencies, directions of changes. It should generalize and present a given subject from a slightly different perspective.

The basic assumptions of graphic presentation (J. Bertin 1967, 1970) can be referred to cartography. A map will fulfill its role when its recipient will be able to properly use it. Beside specific symbolistics of graphics, a map should additionally present information about the arrangement of objects and phenomenon, as well as relations occurring in the geographic space to its user. A well-edited map should inform about the location and main features of the presented phenomenon. An editor-cartographer has to demonstrate his/her ability to select appropriate - methods and forms of cartographic 
presentation. It is worth taking a closer look at the effectiveness of maps which are commonly present in our surroundings. This concerns small-scale thematic maps, complement maps which illustrate press articles or Internet articles, in other words maps which are used for speed

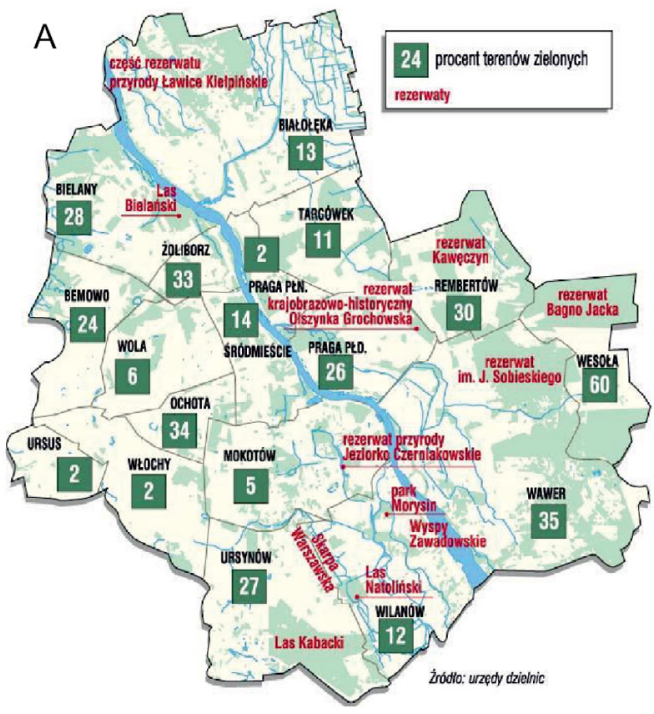

\section{Numbers on maps}

Since the time when maps became popular in the press and on the Internet, one can observe the introduction of new graphic solutions. They include the presentation of quantity data in the

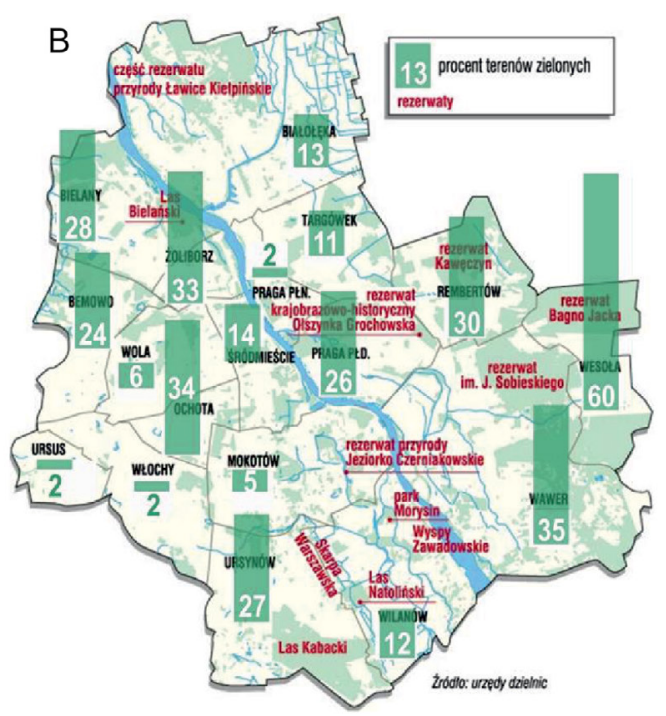

Fig. 1. A - number on the map as an intrinsic method of presentation (www.gazeta.pl), B - as a method of presentation accompanying appropriately scale diagrams (www.gazeta.pl with the author's modification); access date: 27.09 .2013

reading and they should help to find answers to the recipient's questions in a short time. Additionally they should have another feature they should draw the recipients' attention and be attractive to look at.

There are numerous examples of well-edited and poorly edited small-scale thematic maps. They include maps, which are impossible to interpret correctly. They are burdened with methodological defects and they cannot fulfill their task. On the Internet there are also various methodologically correct maps, but they are prepared with no graphic sense. Geographical names are too big, fonts are too sophisticated and there are various unnecessary additions and embellishments which make the presentation difficult to read. There are also examples of good maps: mostly they are simple, readable maps created with no methodological defects. form of numbers placed on the map (fig. 1A). Such a presentation is different from a statistical data in such a way that numbers are treated as features of the objects distributed in geographic space. However they do not have variable size, they are not accompanied by scaled diagrams, and therefore the principle of sufficient symbol visibility is not applied. The map recipient who wishes to find the lowest and the highest value of a given phenomenon is forced to follow all the numbers, comparing their value. Only after further consideration, they are able to try to determine e.g. how often the maximum value is larger than the minimum value. The difference (thirty times larger) is visible when the numbers are accompanies by proportional bars (fig. 1B). Such a presentation seems to respect the principle of logical connection between symbol form and map content, as 
there is hierarchical symbol organization applied. Then the map recipient can perceive the values in the ordinal categories "small-average-large" or read the numerical values. The numbers themselves are not bad, unless they constitute the only form of communication. Added to properly scaled diagrams they can facilitate proper reading of their values.

\section{Graphic redundancy}

Figure 2 also presents the application of numbers on a map. However, this procedure was much more deliberate. The author tried to make the map readable (to follow the principle of sufficient symbol visibility) and used numbers which have been placed in the arrows (directed upward - a positive phenomenon,

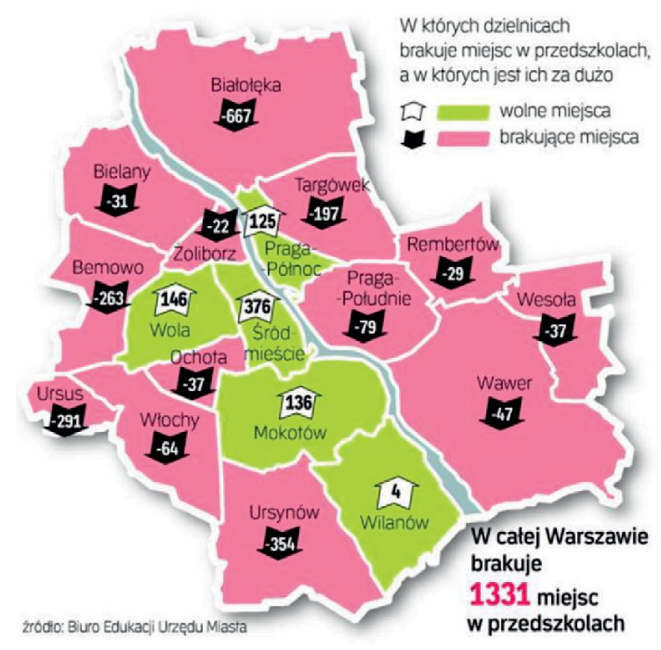

Fig. 2. Graphic redundancy: numbers and colorful based layer on the map (www.gazeta.pl, access date: 25.09 .2013 )

directed downward - a negative phenomenon). The arrows are also distinguished with different colors. However the span between particular values of the phenomenon was not presented in any way, but it is huge (more than 150 times). Additionally, on the map a colorful background was applied which presents the same topic (white arrow - green background - a positive value of the phenomenon, pink arrow - black background - a negative value of the phenomenon). Here we deal with the content redundancy, in other words with the presentation of the same phenomenon using different presentation methods. In such a way the presentation is strengthened, and its user has a better chance to interpret it properly. Certainly, the recipient will pay attention to colors first, and then he/she will read the precise values of the phenomenon (specify the information). However there could be doubts about the used colors for the background which are warm and pleasant. Presenting the opposite phenomenon on a map (excess and lack of vacancies in kindergartens) one could have used the opposite colors (warm - cold).

Graphic redundancy, in other words duplication of graphic measures used to visualize the same issue is a procedure frequently used on maps for speed reading in the press and on the Internet. Figure 3A presents data (average salaries) according to voivodeships both in the form of choropleth map (in four classes), as well as in the form of numbers on the map. One should pay attention to the fact that the numbers have different sizes, but unfortunately it has not been explained. It seems that the size of the numbers corresponds to choropleth classes (four sizes of the numbers). Such a way to strengthen the graphics results in the fact that the user can notice voivodeships with the highest salaries quicker. It is an example of graphic symbol grouping (using sizes and value), in other words the application of the principle of logical connection between symbol form and map content mentioned at the beginning of the article.

A similar procedure of scaling the sizes of numbers was applied in figure 3B. Unfortunately the names of the voivodeship capitals, to which the data was referred were placed on the background, so that the recipient could undoubtedly associate it with the topic of the map - on the background of bank-notes. It is a procedure which was supposed to make the presentation attractive and draw the recipients' attention. It might have been successful, however it was achieved at the cost of the maps readability. The background draws the recipients' attention, but it does not carry any information. Such a graphic procedure makes the recipient focus on what is not important - it distracted them. The principle of graphic balance was not applied, and the presentation aesthe- 

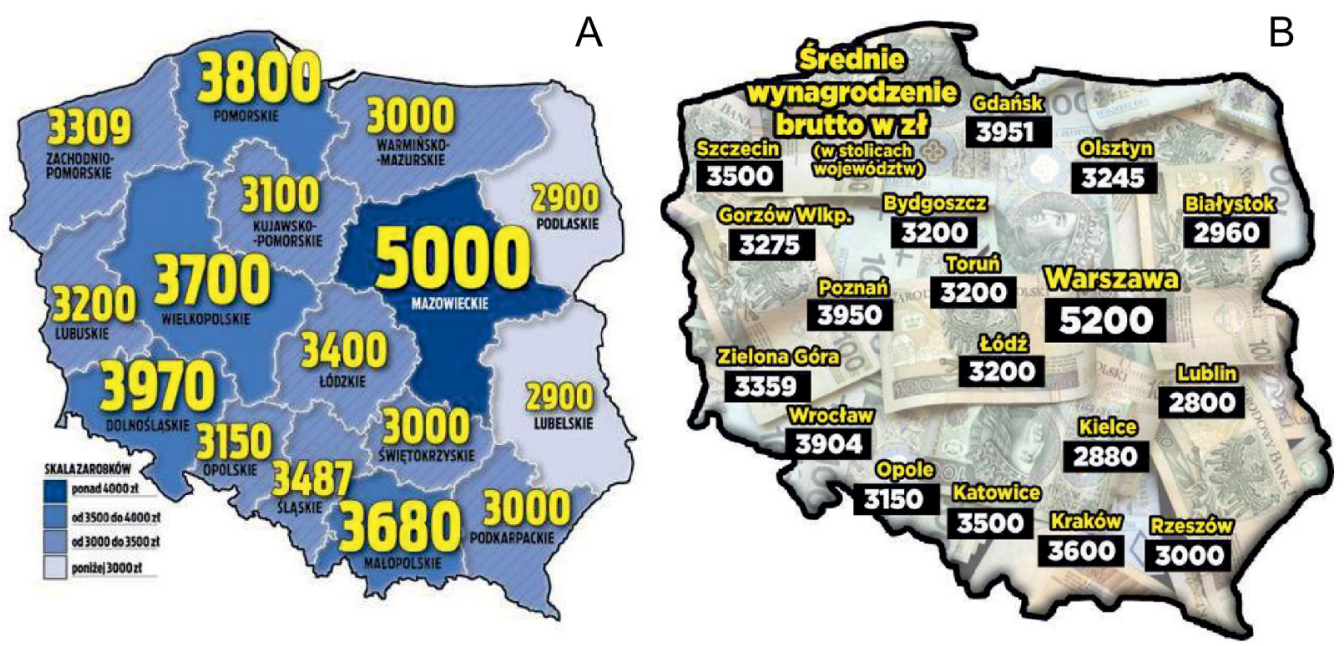

Fig. 3. Numbers on the map in the based layer: A - choropleth map (http://www.se.pl, access date: 22.06.2014) and B - distracting recipients' attention (www.biznes.onet.pl); access date: 19.07.2014

tics leave much to be desired. The choropleth method used as a based layer mentioned before seems to be a significantly better solution.

\section{Excessive reference of the symbol graphic form to the map content}

On the discussed maps additional graphic procedures are frequently used which are supposed to influence the recipient's imagination. An example of such undertaking is the use of bank-note as a background on the map described before (fig. 3A). Sometimes it also occurs that the appearance of a given symbol - diagram refers to the topic. Such a procedure was used in figure $4 \mathrm{~A}$, where fuel prices are presented with a symbol similar to the amount on the display of the petrol station distributor. While the recipient will probably not have problems with such associations, the price differentiation showed on the map will not be easy to read (the amounts differ only by the number after the comma). Certainly the recipient will also have a problem with memorizing the geographic distribution of the phenomenon presented in such a way. Therefore the principle of symbol distinguishability does not apply here, and the principle of simple symbol recognition seems to be overused which makes readability of the map worse.
An excessively strong, and therefore harmful for presentations, tendency to refer with a graphic symbol to the phenomenon presented on the map can be also observed in figure 4B. It presents the average speed in city centers at rush hours. The graphic symbol used here is a diagram in the form of a speedometer located on a car dashboard. Unfortunately, only a small part of the diagram was used to present the changeability of the phenomenon. The speedometer with a range of $0-50 \mathrm{~km} / \mathrm{h}$ and the needle showing the average speed in a given city. On the map cities in which the lowest speed was $35.5 \mathrm{~km} / \mathrm{h}$ and the highest speed was $47.5 \mathrm{~km} / \mathrm{h}$ were presented. Each diagram looks more or less the same, and the needle changes its location only slightly. The only chance to make the graphic presentation more readable is to enter speed average values into the diagrams. Additionally, the author of the map decided to use the background under the numbers and used a 3-degree scale of value there: light orange - with the lowest speed, red and brown with average traffic flow, and dark brown - undistracted traffic flow. This procedure has certainly made the map a little more readable, but it should be remembered that the more sophisticated and complex graphic symbols are used on a map, the more difficult its receipt is. Maybe such symbols lead to associations with the presented issue, but surely they draw the 


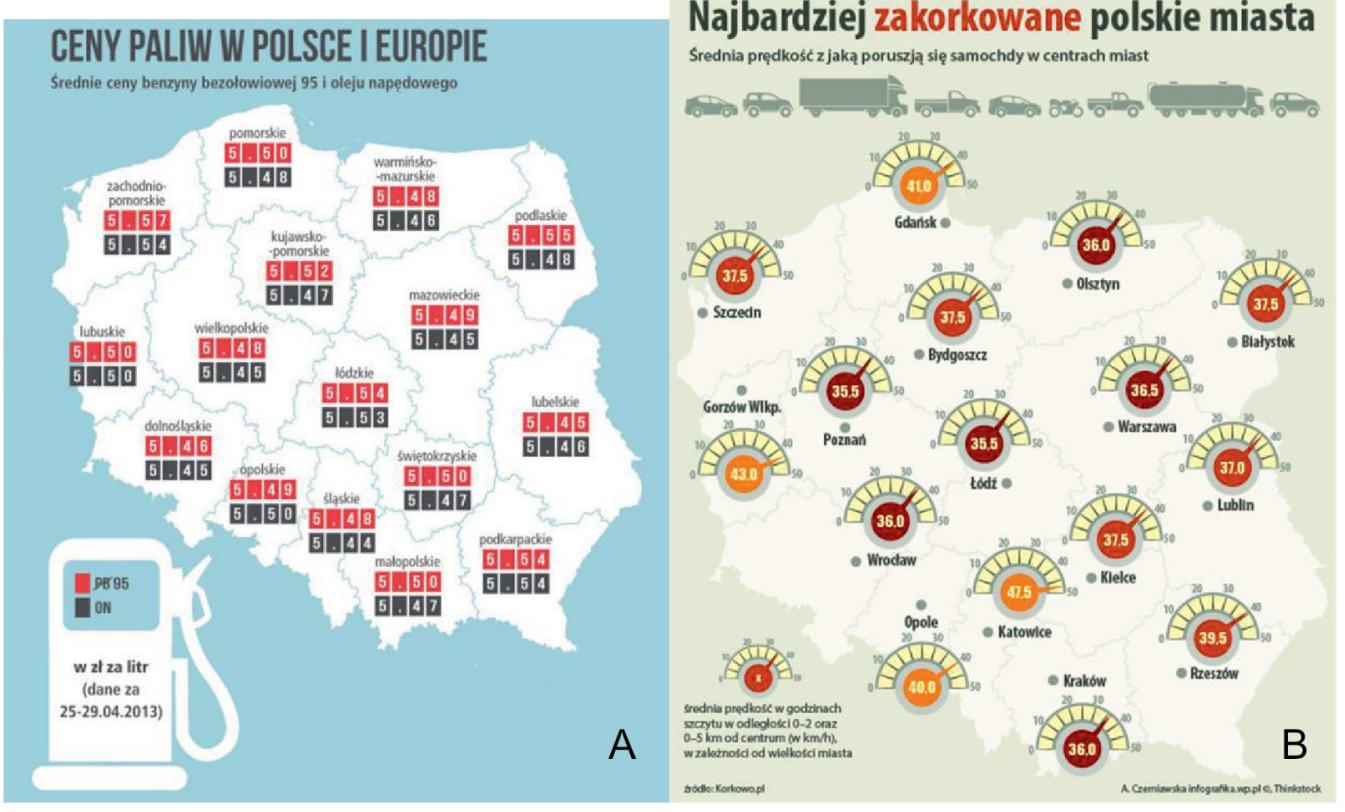

Fig. 4. Symbols excessively relating with their graphic form to the map content (A - www.infografika.wp.pl, access date:13.11.2014; B - www.infografika.wp.pl, access date: 27.11.2013)

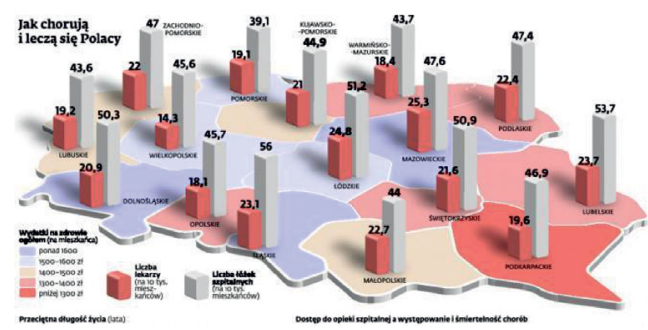

Fig. 5. Embellishing maps by the use of the third dimension (www.forsal.pl, access date: 30.05 .2013 )

users' attention to a single symbol so that it is impossible to read the map as a whole. It is impossible to compare symbols and on their basis draw conclusions in which cities it is easier to drive and in which cities driving at rush hours takes more time. Entering values and introducing changeable value results in the fact that users may try to read the map in general level. However it will not be an effective cartographic message, as the levels of providing information are missing (S. Bonin 1989).

\section{Excessive embellishing of maps and diagrams}

Certainly broad possibilities for computerized preparation of maps significantly accelerate the process of edition, correction and updating maps. Unfortunately they also constitute a simple way to apply incorrect and illogical graphic solutions, and therefore develop maps which are completely unreadable and deprived of logic. Among frequently and willingly used graphic procedures one can include the application of so called third dimensions - a 3D image. In the press and on the Internet it is possible to find numerous examples of graphic embellishing through the use of spatial view (fig. 5). The three-dimensionality of the map in figure 5 has no justification. It is a "disturbed" and deformed shape of Poland and double bars which stick out of it (like out of a plate). Bar diagrams placed in particular voivodeships are difficult to compare if it was not for the numerical values. The principle of sufficient symbol visibility has not been applied here. Adding a third dimension and turning the map has not brought any benefits and it has not resulted in readability of 
the map. However, the map is certainly more attractive graphically and it will be noticed by users quicker.

Three dimensional graphics are frequently used on diagrams which constitute attachments to articles in the press or on the Internet (fig. 6A, B). Such a solution makes it more difficult to read statistical data on the basis of diagrams. In figure $6 \mathrm{~A}$ bars could not be compared correspond to the order from a statistical table. It can be stated that in this case the informative role of a statistical table is exactly the same as of the graph. What is the purpose of a diagram which does not contribute in any way?

It is however possible to come across well-prepared graphic presentations. Sometime the graphics authors themselves suggest a manner of interpreting presented data grouping similar

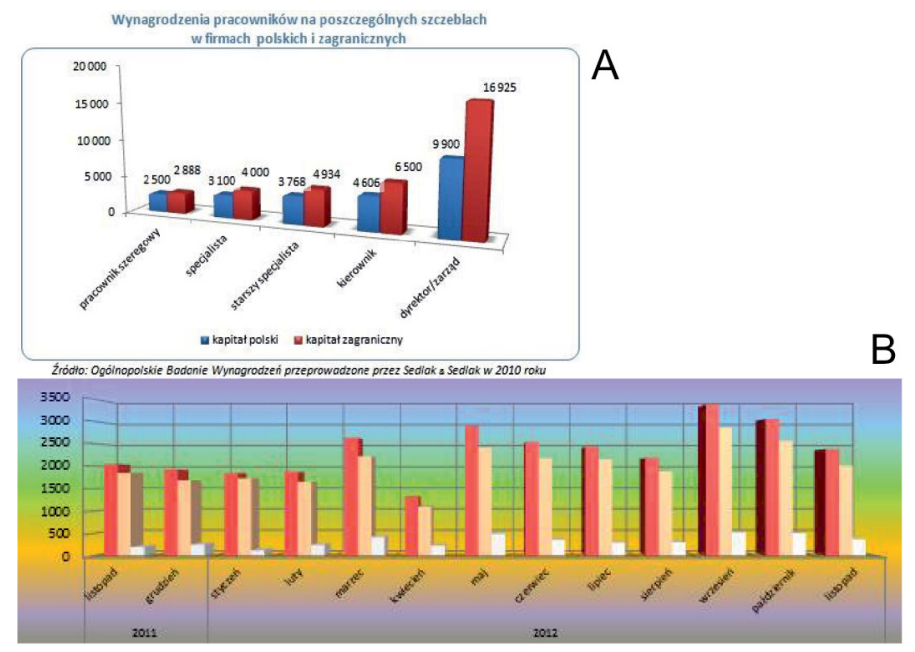

Fig. 6. Embellishing diagrams by the use of the third dimension ( $A-$ www.smarterpoland.pl, access date: 27.02.2015; B - www.obserwatorium.up.podlasie.pl, access date: 1.03.2015)

if the values were not entered. There is no scale which would help to read the values. Therefore the principle of sufficient symbol visibility and correct identification is not applied here. In figure $6 \mathrm{~B}$ the scale was attached, but the whole image is distorted by the imitation of a panoramic view and a colorful shaded background. A disruption to the diagram was introduced in the form of bars shaded from various sides, as if the center of the diagram was extended forward and its edges remained behind. It is a completely unnecessary procedure which distorts simple recognition of the symbols and their methodological correctness. A completely ridiculous graphic procedure was used in figure 7 . The diagrams do not have a scale and they are inclined. Even though data values were entered, the graphics do not fulfill their role. Further bars present average salaries in Poland in successive years. Increasing order of statistical values

\section{ZAROBKI W POLSCE}

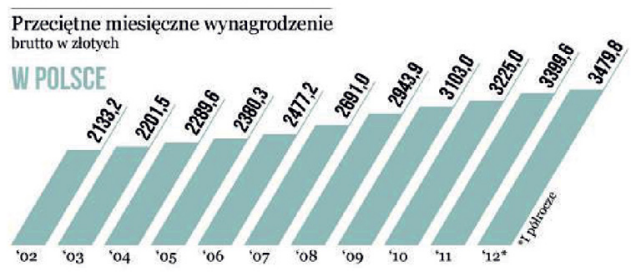

Fig. 7. Unnecessary embellishing of diagrams by the use of their inclination (www.wp.pl, access date: 22.04 .2013 )

values and characterizing them (fig. 8). It is a good example of following the principle of logical connection between symbol form and map content which is synchronized with image organization and graphic symbol grouping. 


\section{Lack of logic in selecting symbols and colors}

A frequently used method of cartographic presentation is choropleth map mentioned before. Popularity of this method of presentation results from an apparent simplicity of its elaborations. It is important to logically select classes statistical data. The manner of selecting class limits should depend among others on the statistical distribution. In computer programs which allow the development of a map there are different ways of appointing choropleth classes available, but there are no instructions how to appropriately apply them. Correctly appointed classes should be illustrated using an appro-

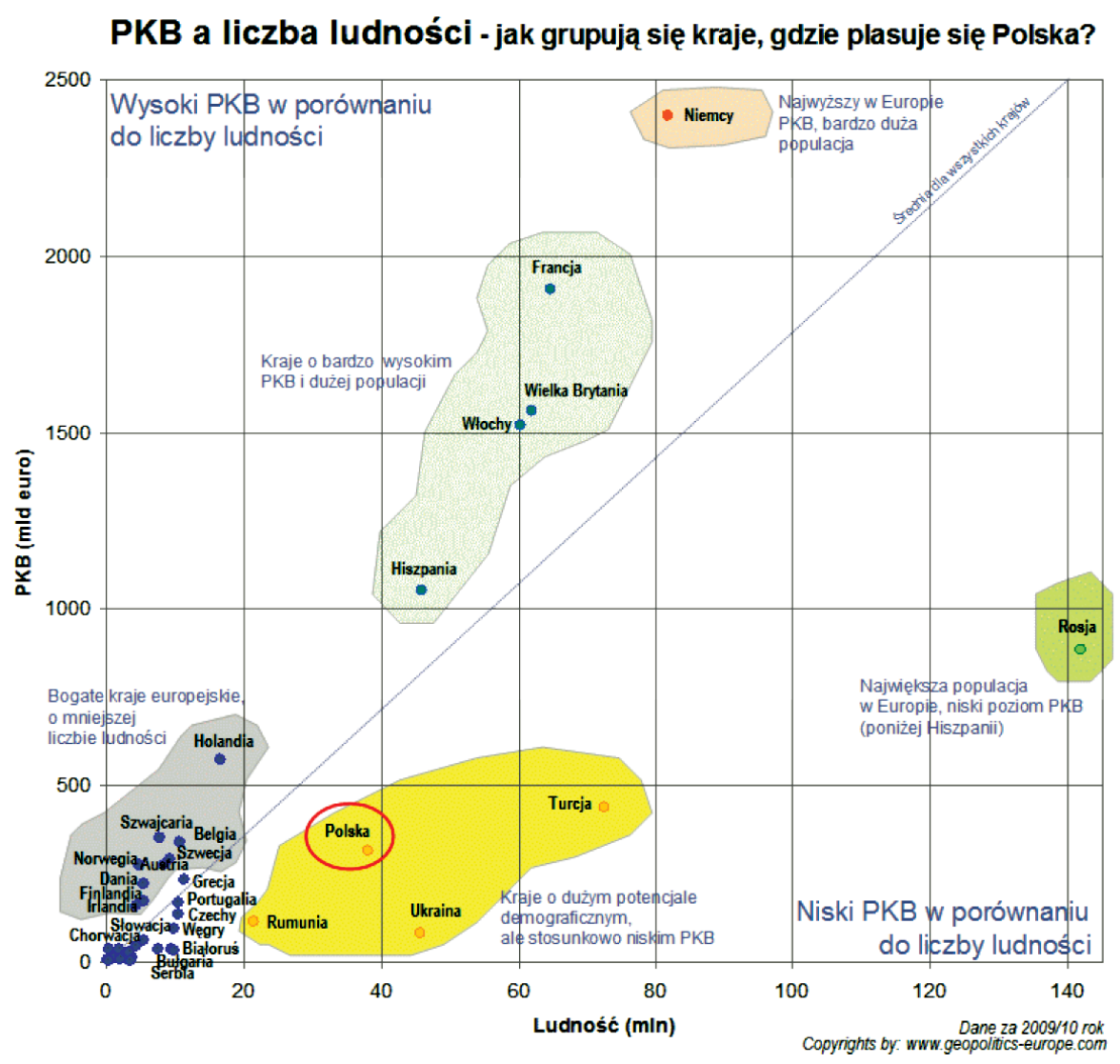

Fig. 8. Diagram with „clues” for recipients (www.geopilitics.com, access date: 12.09.2013)

and corresponding degrees of color scales. It is a necessary condition for the correct interpretation of the map related to the principle of logical connection between symbols and what has been presented on the map. If this condition is not fulfilled, we cannot speak about the correct interpretation of the map. The selection of classes is connected to generalization of the priate color scale, which uses change in valor - a graphic variable which correctly illustrates changeability of phenomenon expressed in a quantitative or ordinal way. It is unacceptable to apply a color variable (fig. 9A,B) which does not allow to order the objects presented on the map. Using different colors (e.g. red, green, blue) and not distinguishing them with valor 
does not make it possible to build a convergent color scale, showing the direction of changes (increase or decrease) of the phenomenon values, therefore it cannot mean a hierarchical organization of applied symbols. One cannot say that such presentations are effective.

On both maps (fig. 9A,B) statistical values are provided, but the analysis of these maps should not involve their interpretation. The user of such a map would find it much more beneficial if he/she could put the objects presented on the map (voivodeships and countries) in the correct order, and indicate where a given pheno- and it supports instead of impeding the interpretation of a given map. It is much easier and quicker to prioritize objects according to their valor degree than according to the analysis of frequently complicated numerical entries. In figure 9B the application of a choropleth method to present absolute data constitutes an additional error.

Another choropleth map was presented in figure 10. It shows the number of births per 1000 residents in particular districts of Warsaw. It should be pointed out that the color scale applied by the author is divergent, and such

\section{B LICZBA MLODYCH LUDZI BEZ PRACY W EUROPIE DANEWTYS.}

$$
\begin{aligned}
& \text { ponižej } 200 \\
& \text { Od } 200 \text { do } 400 \\
& \text { Od } 401 \text { do } 600 \\
& \text { powyżej } 600
\end{aligned}
$$
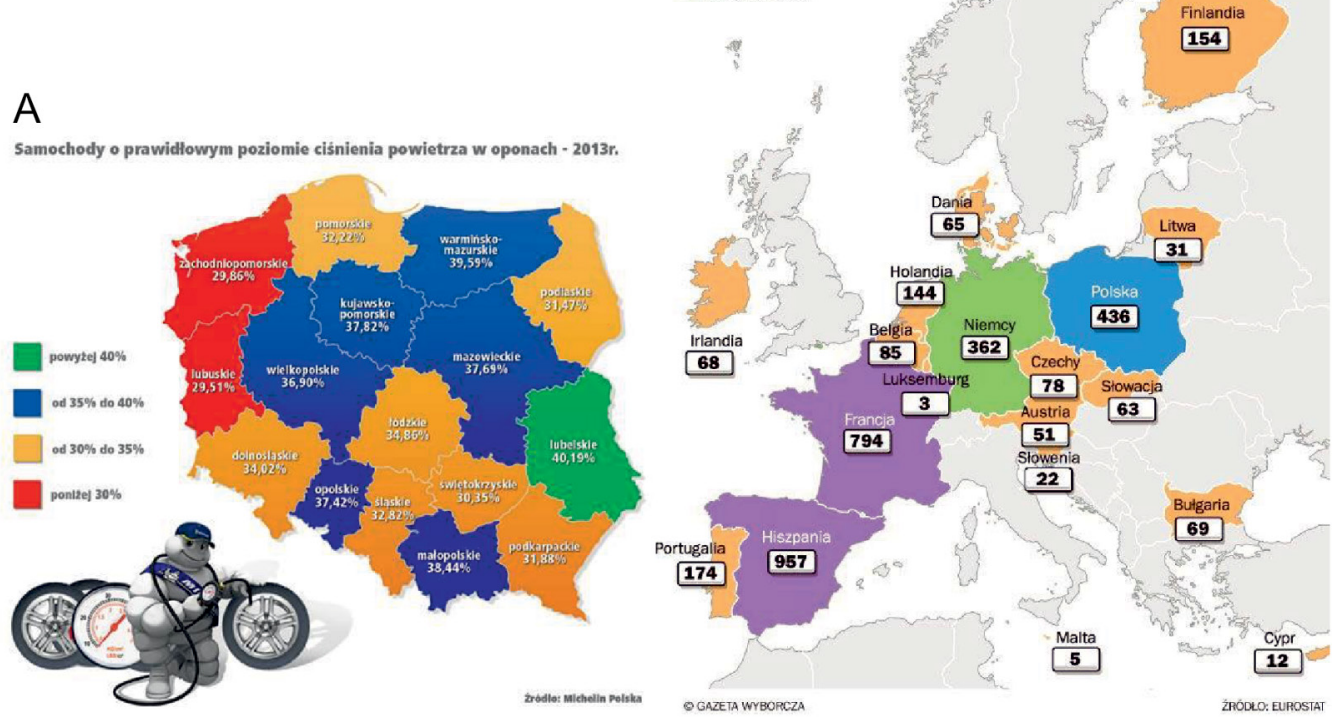

Fig. 9. Lack of logic in the selection of color scale (A - www.wp.pl, access date: 19.09.2013; B - www.gazeta.pl, access date: 21.09 .2013 )

menon has the highest values and where - the lowest, and conclude about spatial relations between particular voivodeships and countries. Reading more about particular statistical values can take place using source materials, e.g. a statistical table. Spatial distribution of a phenomenon is important on the map, and it is better visible when the color scale is correct a scale is used when we wish to present a phenomenon which has positive and negative values and when we wish to expose values above and below an average. Next to the map in the legend an average value for the whole of Warsaw was provided, therefore apparently everything looks methodologically refined. Unfortunately the average value was not taken 
into consideration when appointing classes, it has not become a class limits, and therefore the application of divergent color scale is not correct or justified. In this presentation the principle of logical connection between symbols and the phenomenon presented on the map was violated.

\section{LICZBA URODZEŃ NA TYSIAC MIESZKAŃCÓW}

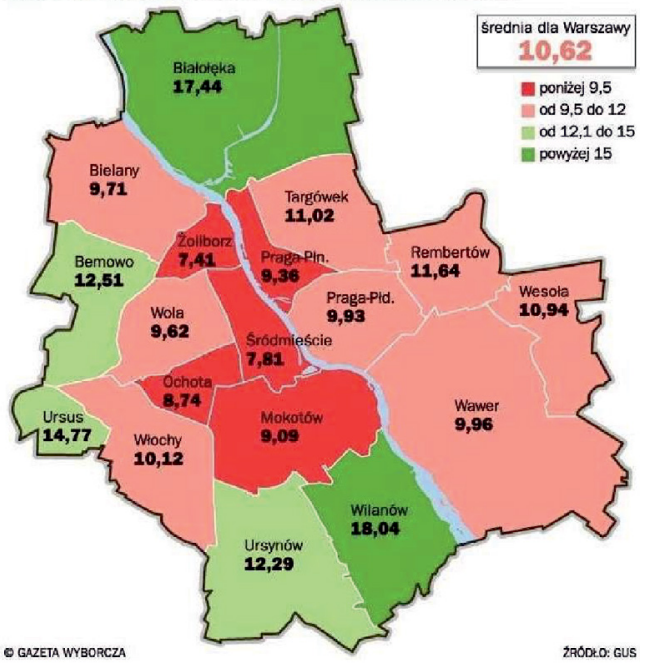

Fig. 10. Lack of logic in the selection of choropleth classes (www.gazeta.pl), access date: 2.10.2013)

\section{Excessive details of a map - lack of content generalization}

"Numbers on maps" discussed in the article can became more complex (fig. 11), when the author wished to present numerous (in this case - three) phenomenon or its features on one map. Introducing numbers on a map does not make it a map supported with research examples. It requires significant focus from the recipient, precise analysis of its content, and only then conclusions. With three sets of numbers in each reference field effective reading of the map is nearly impossible and certainly does not motivate the recipient to analyze the presented content. It is not possible to analyze three spilled collections of numbers simultaneously. A choropleth map with incorrectly se- lected data expressed in absolute terms was placed. It is quite a common mistake resulting from a lack of knowledge of basic principles of cartographic methodology (J. Pasławski 2003, L. Ratajski 1989). Similar issue was presented

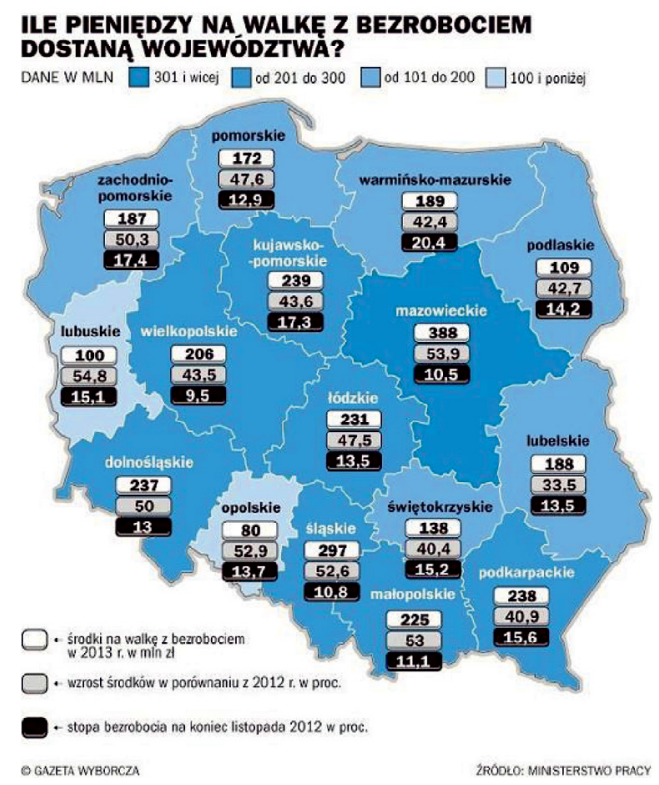

Fig. 11. Excess of numbers on the map as a cartographic presentation (www.gazeta.pl, access date:

12.10.2013)

in figure 12, on which average speeds achieved by drivers in two peaks of increased traffic (morning and afternoon traffic) in the centers of the largest Polish cities was presented in a form of complex diagrams. For each city four values were provided: two in the very center (within 0-2 km from the center) and in its surroundings (within $2-5 \mathrm{~km}$ ). Fortunately the authors realized the difficulty to interpret such a map and they additionally decided to use mixed colors in the diagrams according to the degree of traffic on the streets. Here the logic of selecting colors does not raise any doubts: the fastest drivers were presented on the green background (above $25 \mathrm{~km} / \mathrm{h}$ ), on the grey those driving $20-25 \mathrm{~km} / \mathrm{h}$, and on the red those driving the slowest - below $20 \mathrm{~km} / \mathrm{h}$. Red should be interpreted here as a warning against the largest traffic. 
Figures 11 and 12 are examples of cartographic presentation in which the author seems not to be aware of the perception capabilities of recipients. Entering so much information on the map distorts the graphic balance and cannot bring good results. It is good when such an amount of information is presented not only using numerical entries, but also using graphic variable mentioned before (fig. 12). Then, when following the principle of sufficient symbol visibility there is a chance to keep the presentation at a readable level.

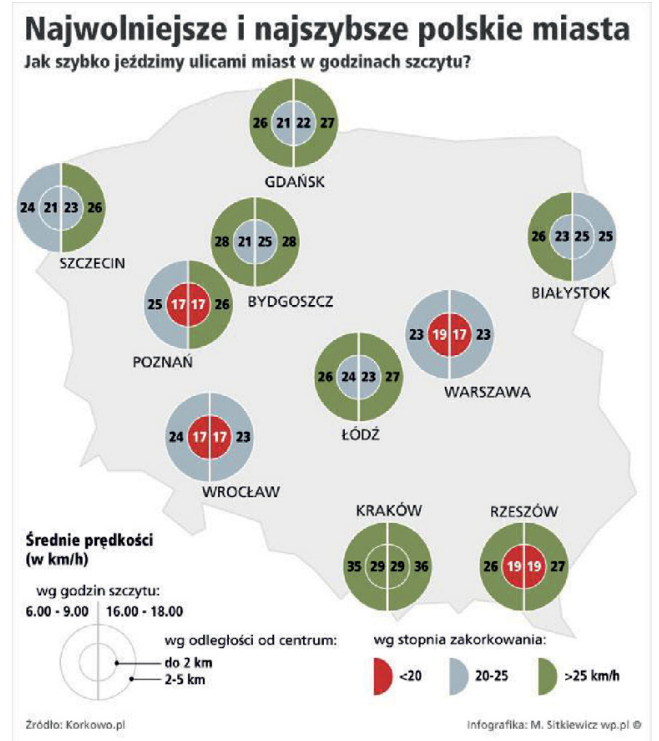

Fig. 12. Numbers on the map as a complex cartographic presentation (www.moto.wp.pl, access date: 20.09.2013)

On the maps found in the press or on the Internet one can frequently notice a tendency of huge generalization or excessive detailness. The expression of the latter feature is the use of numbers on the maps mentioned previously. The lack of sufficient generalization can be also visible in an excessive number of classes and divisions applied on the maps. An example of such "over-estimation" of perception capabilities is the map presented in figure 13, on which the population in Polish cities was presented using fourteen diagrams of different sizes, shapes and colors. It is difficult to discuss dia- gram classes here, as they were described in the legend with individual values. The map is not readable and the principle of sufficient symbol distinguishability has not been followed. In the diagrams phenomenon values were entered, however it does not significantly affect the effectiveness of cartographic message.

Another diagram map (fig. 14) is not effective, either. The population in 19 of the most populated countries in the world was presented with the use of diagrams. Each diagram was filled with the flag of a given country which made the map very colorful. Its graphic attractiveness is not accompanied by effectiveness, as such colorful diagrams are perceived as completely different and it is hard for the recipient to compare their values. Each diagram was completed with the name of a given country, its population

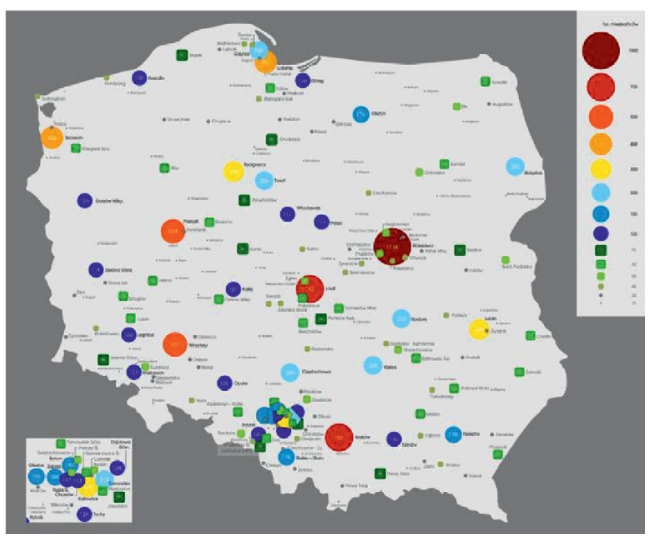

Fig. 13. Excessive minuteness of the map. Lack of logic in the selection of the method and form of presentation (www.pl.wikipedia.org, access date:

15.01.2015)

and the position in the population ranking. It has certainly made the map more readable, but it is still difficult to interpret.

The last examples of increasing and decreasing effectiveness of an cartographic presentations are two maps presenting the level of happiness in the world according to country (fig. $15 A, B$ ). These maps seem to be very different: on map $15 \mathrm{~A}$ a dark background was used, the happiest countries are presented with sad purple color scale, and those with low happiness level were presented with bright orange scale. It seems that the map is perceived as 
gloomy, therefore one can assume that it was used to present such an topic. Looking at map $15 B$, one can get a completely different impression, as the map is bright, joyful and it can

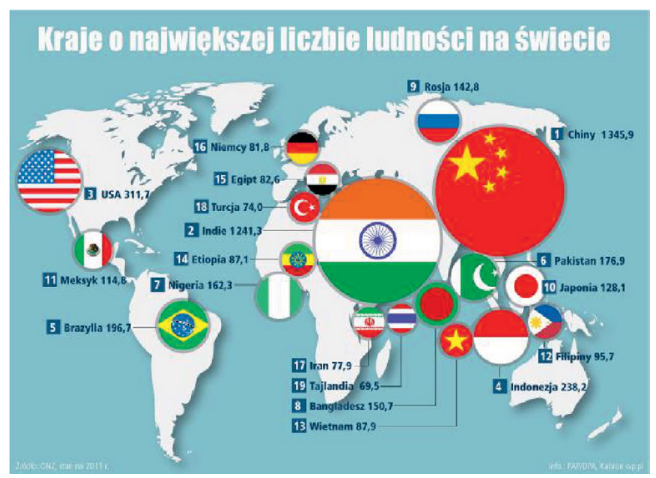

Fig. 14. Effectiveness of the map is not always accompanied by its effective use (www.wp.pl, access date: 12.01 .2014$)$ in the process of preparing small-scale thematic maps used in the press or on the Internet. The purpose of such maps is a possibility of their quick interpretation. On such maps editors' problems with the selection of an appropriate symbol and graphic variable (fig. 1A, 9A) are visible. Sometimes they use symbols which are not sufficiently distinguishable or demonstrative (fig. 11). Supporting maps with research does not increase their readability. Sometime authors try too literally reflect presented phenomenon and therefore the map becomes more difficult to interpret (fig. 4A,B). The lack of graphic sense resulting in the lack of graphic balance and aesthetics constitutes a weak point of numerous cartographic presentations (fig. 13).

Effectiveness of cartographic presentations depends on various factors. They include recipients' perception capabilities and their readiness for reading and interpreting maps, as well

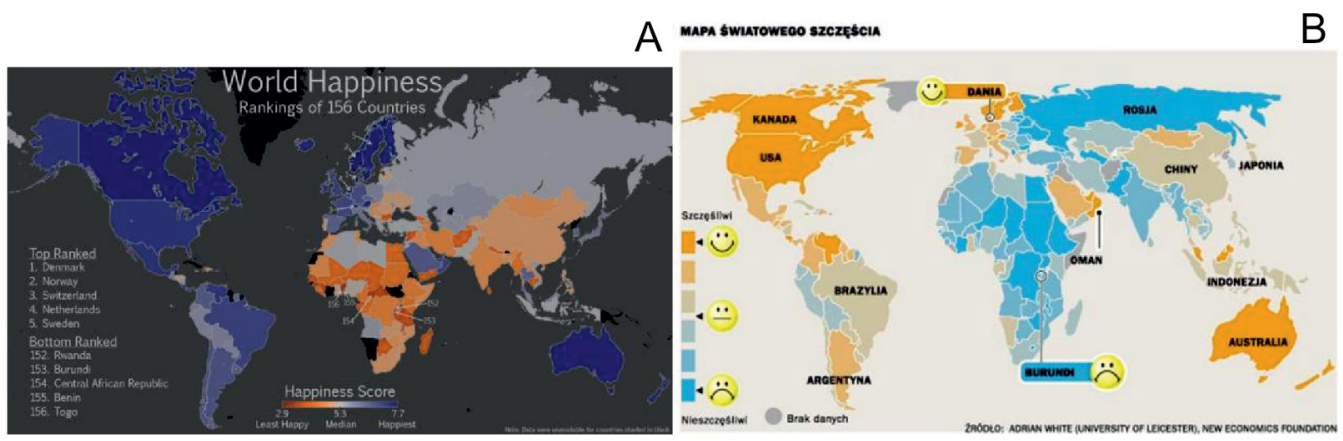

Fig. 15. Selection of colors on the map: A - not adjusted to the presentation topic (www.reddit.com, access date: 26.02 .2015 ), B - well-selected for the presentation topic (http://bi.gazeta.pl); access date: 12.01.2015)

be associated with such an topic. An opposite color scale in comparison to fig. 15A was used, so happiness was presented with orange, and its lack with blue.

\section{Conclusions}

The principles mentioned in the introduction to this article related to graphic design of cartographic presentations are frequently omitted as knowledge and skills of the map editor. It should be pointed out that the qualifications of the map editor should include methodological qualifications supported by the knowledge of the principles for cartographic symbol design, as well as relevant technical qualifications, which allow to properly use the tools to edit a map. Maps facilitate the understanding of texts they accompany and they present relationships between phenomenon better than texts, appealing to the senses. 


\section{References}

Bertin J., 1967, Sémiologie graphique. Les diagrammes, les réseaux, les cartes. La Haye-Paris, Mouton et Gouthier-Villars, 2 ed. 1973.

Bertin J.1970, La graphique."Communications" Vol. 15, pp. 169-185.

Bonin S., 1989, Poziomy czytania mapy. „Polski Przegl. Kartogr." T. 21, nr 2, pp. 49-62.

Chang K.T., 1976, Data differentiation and cartographic symbolization. „The Canadian Cartographer" Vol. 13, no. 1, pp. 60-68.

Kowalski P., Ostrowski W., 2007, Graficzne zasady redagowania w praktyce kartograficznej. In: Kartograficzne programy komputerowe, konfrontacja teorii z praktyką. „Główne problemy współczesnej kartografii”, Wrocław, pp. 19-39.

Meihoefer H., 1969, The utility of the circle as an effective cartographic symbol. „The Canadian Cartographer" Vol. 6, no. 2, pp. 105-117.

Mościbroda J., 1992, Percepcja kartogramów i kartodiagramów jako nośników informacji ilościowej. „Polski Przegl. Kartogr.” T. 24, z. 1-2, pp. 1-17.
Opach T., 2011, Zastosowanie okulografii (techniki eye-tracking) w kartografii. „Polski Przegl. Kartogr.” T. 43, nr 2, pp. 155-169.

Ostrowski W., 1974, Sprawność kartograficznej formy przekazu. „Polski Przegl. Kartogr.” T. 6, nr 1, pp. 14-23.

Ostrowski W., 1979, Semantyczny aspekt sprawności mapy. In: Teoria kartografii. „Prace i Studia Geograficzne" Uniwersytet Warszawski, Wydział Geografii i Studiów Regionalnych, T. 1, pp. 153-224.

Pasławski J., 2003, Jak opracować kartogram. Wyd. II. Warszawa: Wydział Geografii i Studiów Regionalnych UW.

Ratajski L., 1989, Metodyka kartografii społeczno-gospodarczej. Wyd. II. Warszawa-Wrocław, PPWK.

Robinson A.H., 1960, Designing the map. In: A. H. Robinson, Elements of Cartography. 2nd edition. New York, John Wiley, pp. 222-242.

Saliszczew K.A., 1998, Kartografia ogólna. Wyd. 2. Warszawa: Wydawn. Naukowe PWN. 